\title{
Simulation of the occurrence of drought events via copulas
}

\section{Simulação da ocorrência de eventos de secas via cópulas}

\author{
Rogério de Almeida ${ }^{1}$ (D) \& Paulo Sérgio Franco Barbosa ${ }^{1}$ \\ ${ }^{1}$ Universidade Estadual de Campinas, Campinas, SP, Brasil \\ E-mails: dealmeida135@gmail.com (RA),franco.barbosa@gmail.com (PSFB)
}

Received: December 26, 2018 - Revised: September 15, 2019 - Accepted: November 12, 2019

\begin{abstract}
This study presents a method based on Archimedean and Gaussian copulas to simulate the occurrence of hydrological droughts. The droughts were characterized by theory of runs for four threshold levels and six univariate probability distributions were evaluated to represent the probabilistic behavior of their severities and durations. The Akaike Information Criterion was used to select the better univariate probabilistic models, while their hypotheses of goodness-of-fit to the historical data were evaluated by Kolmogorov-Smirnov test. Based on the univariate probability distributions of severities and durations, Archimedean and Gaussian copulas were used in the bivariate analysis of the drought events. The proposed method proves to be a useful tool to simulate the occurrence of drought events, preserving the laws of probability of the severities and durations and the dependency between both.
\end{abstract}

Keywords: Droughts; Hydrological droughts; Archimedean copulas; Gaussian copula; Theory of runs; Frequency analysis.

\section{RESUMO}

Este estudo apresenta um método baseado em cópulas Arquimedianas e Gaussiana para simular a ocorrência de secas hidrológicas. As secas foram caracterizadas pela teoria dos runs para quatro níveis de truncamento e, seis distribuições de probabilidade uni-variadas foram avaliadas para representar o comportamento probabilístico de suas severidades e durações. O Critério de Informação de Akaike foi usado para selecionar os melhores modelos probabilísticos uni-variados, enquanto que, suas hipóteses de aderência aos dados históricos foram avaliadas pelo teste de Kolmogorov-Smirnov. Tendo como base as distribuições de probabilidade das severidades e durações, copulas Arquimedianas e Gaussiana foram utilizadas na análise bivariada dos eventos de seca. O método proposto se mostra como ferramenta viável para simular a ocorrência de eventos de seca, preservando as leis de probabilidade das severidades e durações e a dependência entre ambas.

Palavras-chave: Secas; Secas hidrológicas; Cópulas arquimedianas; Cópula gaussiana; Teoria dos runs; Análise de frequência. 


\section{INTRODUCTION}

Droughts are complex phenomenon and their impacts vary from region to region and generally are associated with periods whose precipitation levels are insufficient. The droughts are perceived in different ways in various parts of the world. According to Hudson \& Hazen (1964), this diversity of perceptions can be observed in the periods used to characterize the droughts, e.g.: (a) any period of 6 days or more without precipitation in Bali, Indonesia; (b) 2 years or more without precipitation in Egypt; (c) any year on the Nile River without flooding, regardless of any precipitation level.

The deficiency of precipitation is considered as the primary cause of the droughts while the effects on water resources system of a region are considered as secondary causes or drought impacts, e.g., low river streamflow and low soil moisture. Thus, if the interest is to study the causes of the droughts, attention should be focused on precipitation, but if the interest is to study the impacts of the droughts, attention should be focused, e.g., on the streamflow or soil moisture data (Dracup et al., 1980a). In this context, the droughts can be classified according to the nature of the deficits (Dracup et al., 1980a; Beran \& Rodier, 1985; Wilhite \& Glantz, 1985; Mishra \& Singh, 2010): (a) meteorological droughts, when a lack of precipitation occurs during a period over a region; (b) agriculture droughts, when the soil moisture is insufficient to support crops; (c) hydrological droughts, when the surface and underground water resources are inadequate to support their respective uses and; (d) socio-economical droughts, when the economic activities and people's lives are impacted by the lack of water supply .

The impact of the droughts depends on the several factors, e.g., social vulnerability of the region, the weather, the multiple water uses across the river basin or the region, etc. Generally, a drought is derived from low-impact cumulative events over time, as opposed to floods, earthquakes and cyclones, which are high-impact extreme events (Cunha et al., 1983).

The droughts can be treated from two viewpoints: conceptual and operational. From a conceptual viewpoint the definition of the drought is in relative terms, e.g., "a dry period", "a severe drought", providing little guidance. While, from the operational viewpoint, the definitions use the frequency analysis of the severities or durations for a given historical period (Mishra \& Singh, 2010). Thus, to study the droughts' impacts, a clear definition is needed, e.g., which indicates when a drought event starts and ends, and what its impact.

In 1967, Yevjevich published the paper entitled "An objective approach to definitions and investigations of continental hydrologic droughts", where he introduced a threshold procedure denominated of "theory of runs" to identify and characterize hydrological droughts. Since then, the threshold procedure has been used in drought studies, regardless of its nature (meteorological, hydrological and agricultural).

The theory of runs allows defining the main characteristics of a drought event. According to Yevjevich (1967), from a threshold level it is possible to define the characteristics of a drought event, e.g., its duration and its severity. The duration corresponds to the period in which the interest variable (e.g., streamflow or precipitation) is below the threshold level, while the severity is the cumulative volume of the variable associated with the duration.

Drought studies have been received attention from researchers around the world since they are indispensable tools for water resource planning and management. The theory of runs allowed several researchers to conduct univariate analyses of the main variables of the hydrological droughts (severities and durations), as can be seen in Yevjevich (1967), Millian \& Yevjevich (1971), Dracup et al. (1980b), Zelenhasic \& Salvai (1987), Sen (1990), Chang (1990), Wijayaratne \& Golub (1991), Mathier et al. (1992), Sharma (1997), Cancelliere \& Salas (2004), Tesfaye (2005), Yahiaoui et al. (2009), Panu \& Sharma (2009), Sharma \& Panu (2010), Akyuz et al. (2012) and Sharma \& Panu (2014). These studies are considered as references for the univariate analysis of the severities and durations of the droughts.

The main variables used to describe the drought events, severities and durations, are strongly correlated and this characteristic is not considered in univariate analyze. In this context, the multivariate analyze allows us to consider the correlation between these variables.

Thus, the multivariate analysis of droughts has been the focus of attention by many researchers. Shiau \& Shen (2001) and Salas et al. (2005) obtained joint probability distribution of severities and durations based on the product of the severities' conditional probability distribution (for a given duration) by the durations' probability distribution. In this case, to obtain the conditional probability distributions, a larger data samples are required and it is not always available in the historical data. Thus, the researchers used techniques such as generation of time series to increase sample size.

The copulas, introduced by Sklar in 1959, have been an alternative used by several researchers for the multivariate analysis of droughts. Copulas are functions that link univariate probability distributions of random variables preserving the dependency between them (Sklar, 1959; Nelsen, 2006; Joe, 1997).

The concept of copula has started to be used in hydrology from 2003 with the first application in rainfall modeling (Michele \& Salvadori, 2003). Important contributions on the subject also can be found in Salvadori et al. (2007), Salvadori \& Michele (2007) and Genest \& Favre (2007). In the study of the meteorological droughts can be mentioned, among others, the works of Michele \& Salvadori (2003), Shiau (2006), Shiau \& Modarres (2009), Mirabbasi et al. (2011), Ganguli \& Reddy (2012), Reddy \& Ganguli (2012), Ekanayake \& Perera (2014), Wang et al. (2017), Fan et al. (2017), Tosunoglua \& Onof (2017), She \& Xia (2018) and Azam et al. (2018).

In the study of the hydrological droughts can be mentioned, among others, the works of Shiau et al. (2007), Kwak et al. (2012), Michele et al. (2013), Salvadori \& Michele (2015), Hamdi et al. (2016), Kwak et al. (2016a), Kwak et al. (2016b), Zhao et al. (2017) and Dodangeh et al. (2017). These studies focus exclusively on the bivariate analysis of the joint return period of the severities and durations of the drought events.

The objective of this study is to present a method to simulate the occurrence of drought events using a bivariate analysis of the severities and durations based on Archimedean and Gaussian copulas. 


\section{MATERIALS AND METHODS}

Study and area data

In this study, the characteristics' droughts of the Camanducaia River, located in the southeast region in Brazil, were evaluated. The Camanducaia River basin is located in the Unit of Management of Water Resources 5 (UGRHI 5) composed of the river basins of the Piracicaba, Capivari and Jundiai Rivers. The UGRHI 5 is part of the Tietê River basin located in the State of São Paulo (Figure 1).
The Camanducia River basin has a drainage area of $1,032 \mathrm{~km}^{2}$, where $860 \mathrm{~km}^{2}$ are located in the State of São Paulo, and the other part located in the State of Minas Gerais. The Camanducaia River has no storage reservoir and is responsible for the total or partial water supply of 11 cities in the region (Figure 2).

The Camanducaia River is also the main stream affluent of the Jaguari River, which is an important component of water supply in the region and is part of the Cantareira System that supplies water to the Metropolitan Region of São Paulo with more than 10 million people.

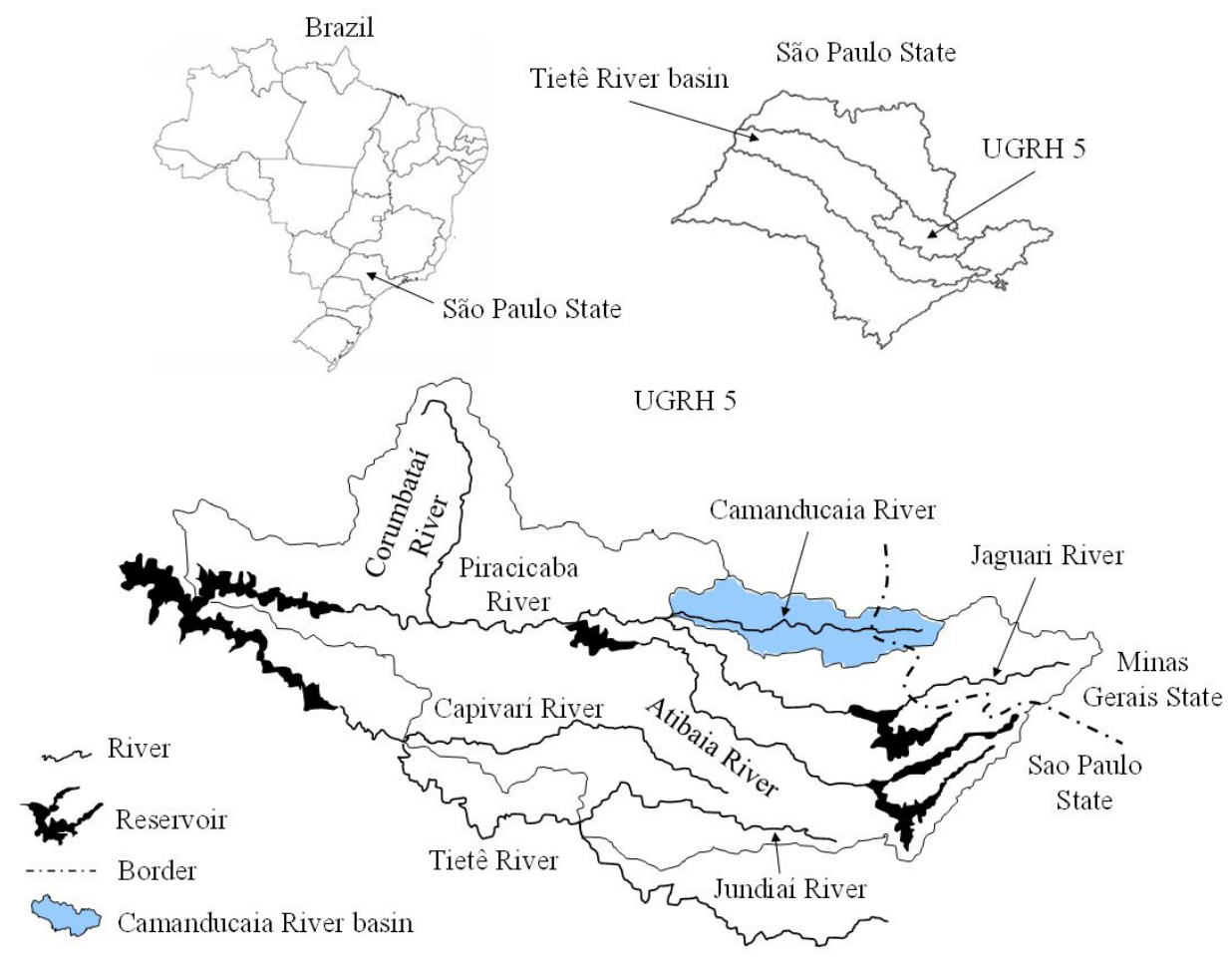

Figure 1. Region of the Camanducaia River basin.

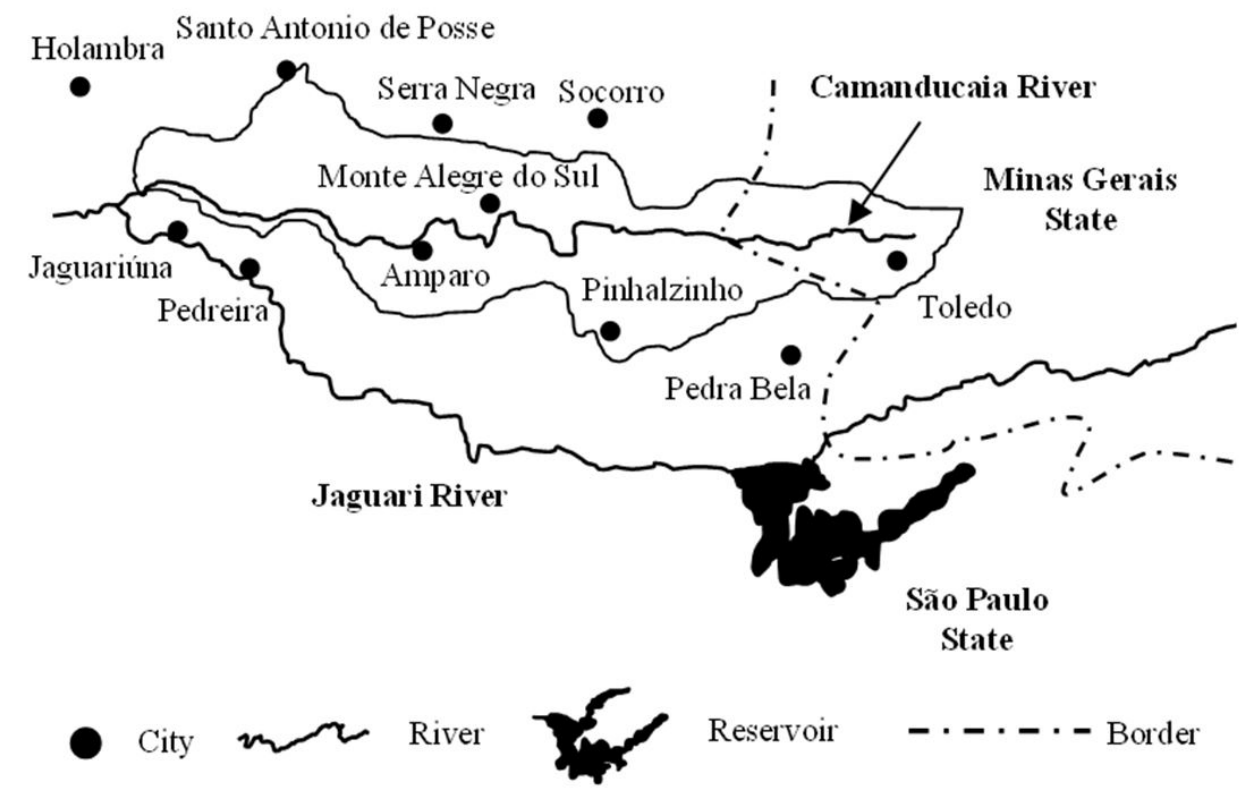

Figure 2. Camanducaia River basin and cities supply it. 
The monthly streamflow data of the streamflow gauging station 3D-002 located in Monte Alegre do Sul city, Latitude $22^{\circ} 41^{\prime} 44^{\prime \prime}$ and Longitude $46^{\circ} 40^{\prime} 25^{\prime \prime}$ were used. The streamflow data has 876 monthly records from January 1944 to December 2016 (73 years). Only eight monthly streamflow records required estimations. Figure 3 shows historical data of average monthly streamflow from the streamflow gauging station 3D-002 located in Monte Alegre do Sul city. The main statistics of the streamflow data for the streamflow gauging station 3D-002 are shown in Table 1. The Camanducaia River data were extracted from São Paulo Integrated Water Resources Management System (Sistema Integrado de Gerenciamento dos Recursos Hídricos, 2017).

Table 1. Main statistics of the streamflow data for the Camanducaia River (streamflow gauging station 3D-002).

\begin{tabular}{cc}
\hline Statistics & Value $\left(\mathrm{m}^{3} / \mathrm{s}\right)$ \\
\hline Long term average & 6.80 \\
Median & 5.44 \\
Standard deviation & 4.39 \\
Maximum & 35.53 \\
Minimum & 0.69 \\
\hline
\end{tabular}

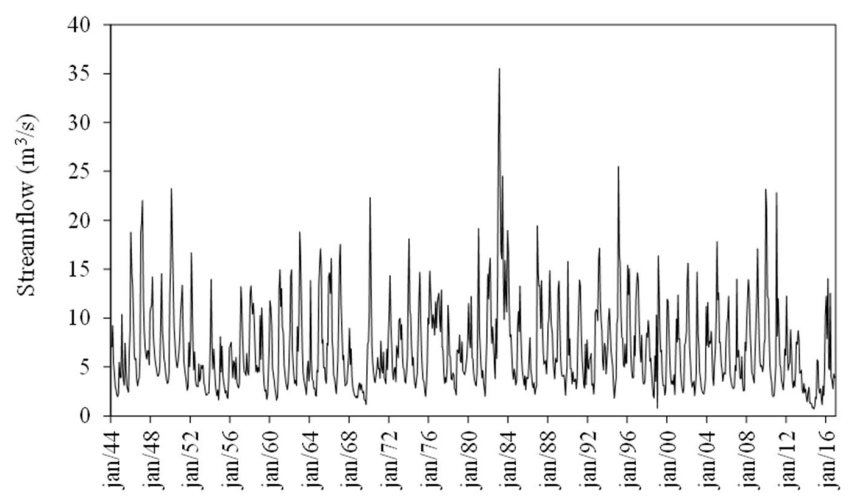

Figure 3. Average monthly streamflow of the Camanducaia River from 1944 to 2016 (streamflow gauging station 3D-002).

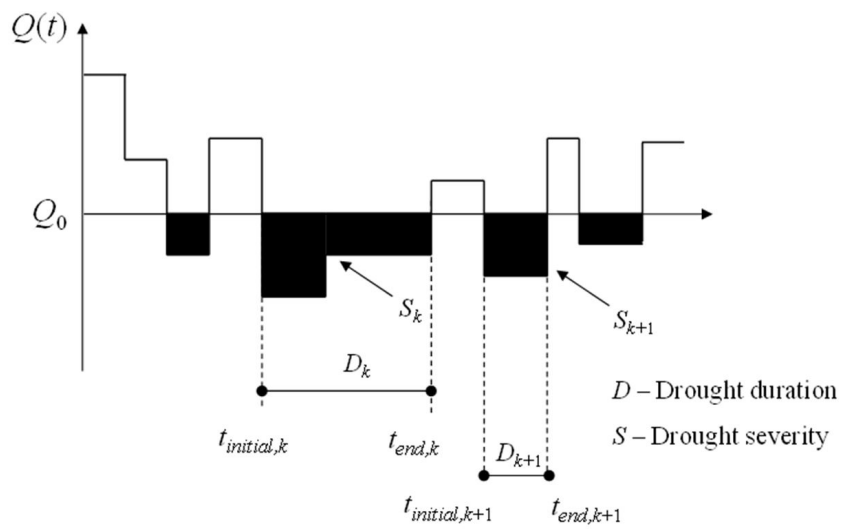

Figure 4. Theory of runs applied to define and characterize the drought events.

\section{Characterization of drought events}

Let $Q_{0}$ the threshold level or truncation level, a drought event starts when the streamflow $Q(t) \leq Q_{0}$ remaining until $Q(t)>Q_{0}$.

When the threshold level is applied in the streamflow time series, a sample containing multiple drought events is generated, where each event is characterized by its severity $\left(S_{k}\right)$ and duration $\left(D_{k}\right)$. Figure 4 shows the application of the theory of runs for the definition and characterization of the drought events considering a constant threshold level equal to $Q_{0}$.

For $Q(t)<Q_{0}$ the duration of a drought event is calculated by:

$D_{k}=\sum_{t=t_{\text {intial }, k}}^{t_{\text {end }, k}} \Delta t$

where $D_{k}$ is the duration for the $k$-drought event, $t_{\text {initial }, k}$ and $t_{\text {end }, k}$ are the start and end time of the $k$-drought event, and $\Delta t$ is the time step of $t$ (daily, weekly, monthly or yearly).

For $Q(t)<Q_{0}$ the severity of a drought event is calculated by:

$S_{k}=\sum_{t=t_{\text {intital }, k}}^{t_{\text {end }, k}}\left[Q_{0}-Q(t)\right] \cdot \Delta t$

where $S_{k}$ is the severity of the $k$-drought event, $t_{\text {initial }, k}$ and $t_{\text {end }, k}$ are the start and end time of the $k$-drought event, $Q(t)$ is the streamflow at time $t$, and $Q_{0}$ is the threshold level.

The main variables (severity, duration, number of events) and, mainly, the probability distributions of the severities and durations depend on the threshold level. The threshold level may also influence the dependence structure of the drought events.

In this study, the drought events were characterized for four constant threshold levels corresponding to 98th, 95th, 92th and 90th percentiles of the flow-duration curve based on the historical data of average monthly streamflow, also called P98, P95, P92 and P90, respectively. The threshold levels are represented by low values of streamflow with high probability of being exceeded.

Figure 5 shows the scatter plot of the severities and durations of the drought events for the Camanducaia River considering the threshold levels P98, P95, P92 and P90 for the monthly streamflow data from 1944 to 2016.

Table 2 shows the main characteristics of the drought events of the Camanducaia River obtained by the theory of runs, as the number of events, the average (Ave), maximum (Max) and minimum (Min) values of the severities and durations and the concordance measures between both, represented by Kendall's $\tau$ and Spearman's $\rho$.

The use of the theory of runs to obtain drought events can generate events that are very close, and therefore, dependent on each other. According to Zelenhasic \& Salvai (1987), the dependence between these drought events can be deal by arbitrary simplifications, such as not considering events with insignificant severity and/or considering subsequent events as a single event, provided there is a relatively short time interval between them where $Q(t)>Q_{0}$.

The Box-Pierce and Ljung tests were used to evaluate the hypothesis of independence of the observations in series for the severities and duration of the drought events from the historical data considering a $95 \%$ significance level. According to the p-values of the tests, all greater than 0.05 , the hypothesis of independence 


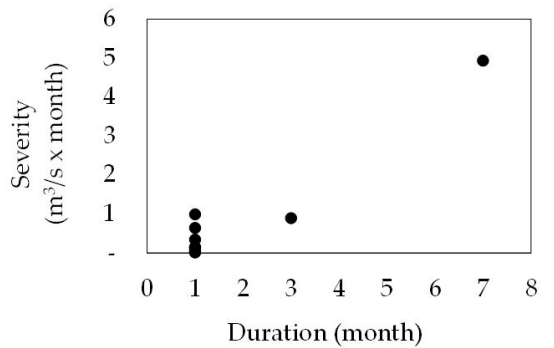

(a)

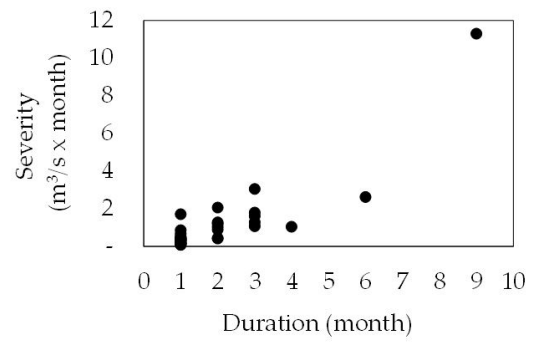

(c)

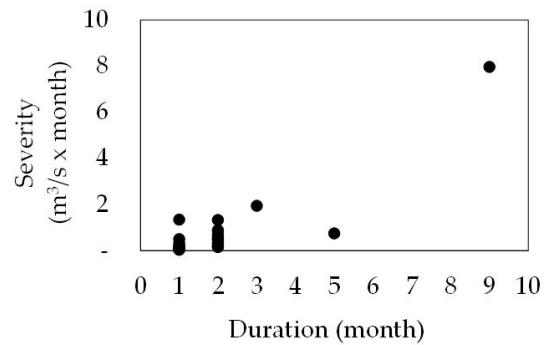

(b)

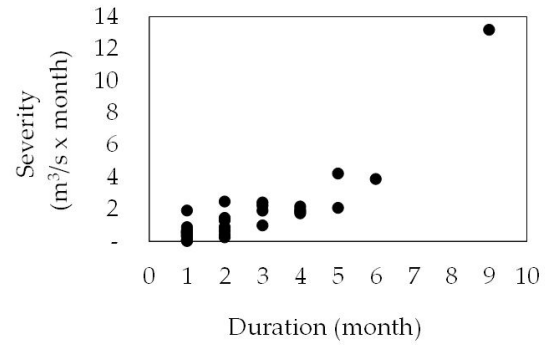

(d)

Figure 5. Durations and severities of the drought events for the Camanducaia River from 1944 to 2016 considering the threshold levels: (a) P98, (b) P95, (c) P92 and (d) P90.

Table 2. Main characteristics of the drought events for the Camanducaia River from 1944 to 2016.

\begin{tabular}{|c|c|c|c|c|c|}
\hline \multirow{2}{*}{\multicolumn{2}{|c|}{ Characteristics of the drought events }} & \multicolumn{4}{|c|}{ Threshold level } \\
\hline & & P98 & P95 & P92 & $\mathbf{P 9 0}$ \\
\hline \multicolumn{2}{|c|}{ Number of events } & 10 & 21 & 37 & 40 \\
\hline \multirow[t]{3}{*}{ Severity } & Ave & 0.82 & 0.85 & 1.07 & 1.41 \\
\hline & Max & 4.94 & 7.97 & 11.30 & 13.19 \\
\hline & Min & 0.01 & 0.03 & 0.08 & 0.02 \\
\hline \multirow[t]{3}{*}{ Duration } & Ave & 1.80 & 2.05 & 1.89 & 2.20 \\
\hline & Max & 7 & 9 & 9 & 9 \\
\hline & Min & 1 & 1 & 1 & 1 \\
\hline \multicolumn{2}{|c|}{ Kendall's $\tau$} & 0.55 & 0.58 & 0.78 & 0.63 \\
\hline \multicolumn{2}{|c|}{ Spearman's $\rho$. } & 0.62 & 0.67 & 0.77 & 0.78 \\
\hline
\end{tabular}

Note: Severity in ( $\left.\mathrm{m}^{3} / \mathrm{s} \times \mathrm{month}\right)$ and duration in (month).

for the observations in series cannot be rejected (Table 3). Thus, the use of the simplifications proposed by Zelenhasic \& Salvai (1987) was not necessary.

\section{MARGINAL DISTRIBUTION OF PROBABILITY OF THE SEVERITIES AND DURATIONS}

In this study, six-univariate probability distributions for severities and durations of the drought events of the Camanducaia River were tested: 2-parameters Gamma (GAM2), Exponential (EXP), Weibull (WBL), Log-Normal (LOGN), Generalized Pareto (GP) and Generalized Extreme Value (GEV).

Table 4 shows the univariate probability distributions, their density functions with their parameters.

The parameters of the univariate probability distributions were estimated by Maximum Likelihood Estimation (MLE) method. The selection of the better univariate probabilistic model and the verify of its hypothesis of goodness-of-fit to the historical data were made by AIC and KS test, respectively. The KS test's p-value was calculates by Monte Carlo simulation with a significance level
Table 3. p-Values of the Box-Pierce and Ljung tests for observations in series of the severities and durations of the drought events for the Camanducaia River from 1944 to 2016.

\begin{tabular}{cccccc}
\hline \multirow{2}{*}{$\begin{array}{c}\text { Threshold } \\
\text { level }\end{array}$} & \multicolumn{4}{c}{$\mathrm{p}$-Values } \\
\cline { 2 - 3 } \cline { 2 - 3 } \cline { 5 - 6 } & Box-Pierce & Ljung & & Box-Pierce & Ljung \\
\hline P98 & 0.51 & 0.44 & & 0.57 & 0.52 \\
P95 & 0.60 & 0.68 & & 0.67 & 0.65 \\
P92 & 0.78 & 0.77 & & 0.82 & 0.81 \\
P90 & 0.77 & 0.77 & & 0.91 & 0.91 \\
\hline
\end{tabular}

of $95 \%$. Thus, for p-values greater than 0.05 the hypothesis of goodness-of-fit cannot be rejected.

\section{COPULAS}

Copulas are functions that link univariate probability distributions to form a multivariate probability distribution and it were first suggested by Sklar in 1959. 
According to Sklar (1959), if $H$ is a joint probability distribution with margins $F_{1}$ and $F_{2}$, then there exists a twodimensional copula $C$ such that for all $\boldsymbol{x}=\left(x_{1}, x_{2}\right)$ in $\bar{R}^{2}=[-\infty,+\infty]^{2}$ :

$H\left(x_{1}, x_{2}\right)=C\left(F_{1}\left(x_{1}\right), F_{2}\left(x_{2}\right)\right)$

Equation 3 is known as Sklar Theorem.

Corollary 1: If $C$ is a copula, $H$ is a joint probability distribution with margins $F_{1}$ and $F_{2}$ and $F_{1}^{(-1)}$ e $F_{2}^{(-1)}$ are the inverses of $F_{1}$ and $F_{2}$ to all $\boldsymbol{u}=\left(u_{1}, u_{2}\right)$ in $I^{2}=[0,1]^{2}$ :

$C\left(u_{1}, u_{2}\right)=H\left(F_{1}^{(-l)}\left(u_{1}\right), F_{2}^{(-1)}\left(u_{2}\right)\right)$

Table 4. Univariate probability distributions tested for the severities and durations of the drought events.

\begin{tabular}{|c|c|}
\hline Probability distribution & Probability density functions \\
\hline GAM2 & $f(x)=\frac{1}{\beta^{\alpha} \Gamma(\alpha)} x^{\alpha-1} e^{-\frac{x}{\beta}}$ \\
\hline EXP & $f(x)=\lambda e^{-\lambda x}$ \\
\hline WBL & $f(x)=\frac{\alpha}{\beta}\left(\frac{x}{\beta}\right)^{\alpha-1} e^{-\left(\frac{x}{\beta}\right)^{\alpha}}$ \\
\hline LOGN & $f(x)=\frac{1}{x \sigma \sqrt{2 \pi}} e^{-\frac{(\ln (x)-\mu)^{2}}{2 \sigma^{2}}}$ \\
\hline GP & $f(x)=\frac{1}{\sigma}\left(1+\frac{\xi(x-\mu)}{\sigma}\right)^{\left(-\frac{1}{\xi}-1\right)}$ \\
\hline GEV & $\begin{array}{c}f(x)=\frac{1}{\sigma} t(x)^{\xi+1} e^{-t(x)} \\
\text { wheret }(x)=\left\{\begin{array}{c}\left(1+\xi\left(\frac{x-\mu}{\sigma}\right)\right)^{-\frac{1}{\xi}} \text { if } \xi \neq 0 \\
e^{-\frac{(x-\mu)}{\sigma}} \text { if } \xi=0\end{array}\right.\end{array}$ \\
\hline
\end{tabular}

Note: $\alpha, \beta, \lambda, \mu, \sigma$, and $\xi$ parameters.
Based on the Corollary 1, the copula is a multivariate probability distribution, with univariate probability distributions, which contains the information on how the variables depend on each other.

The copulas are divided into families, which try to model the most varied types of dependency between variables, such as: Elliptical (Normal, or Gaussian, and t); (b) Archimedean (Clayton, Gumbel, Frank, Ali-Mikhail-Haq and Joe); (c) Extreme Value (Gumbel, Galambos, Husler-Reiss, Twan and t-EV); and (d) and others (Plackett and Farlie-Gumbel-Morgenstern). These copulas can be found in R package "copulas". Others packages provide many more alternatives.

A common fact in the drought studies is the reduced number of events observed from historical data. The reduced number events can indicate a false perception of water safety, since the observed events from historical data may not be critical in terms of durations, severities or both. Thus, as the severities and durations of the droughts are highly correlated, the copulas are presented as alternatives to simulate the occurrence of events, preserving the correlations and the probability laws these variables.

In this study, six copulas were tested for the bivariate analysis of the severities and durations of the drought events for the Camanducaia River, being five Archimedean copulas, Clayton (CLA), Frank (FRA), Gumbel (GUM), Joe (JOE) and Ali-Mikhail-Haq (AMH), and one Elliptical copula of the Gaussian type (GAU). Table 5 shows the copulas used in this study, their functions, and their parameters.

The copulas parameters were estimated by the Maximum Pseudo-Likelihood (MPL) method. The selection of the better bivariate model and the verify of its hypothesis of goodness-of-fit to the historical data were made by AIC and Goodness-of-Fit test (GOF), respectively. The GOF test's p-value was calculate by a parametric bootstrap according to Genest \& Rémillard (2008) with a significance level of $95 \%$. Thus, for $\mathrm{p}$-values greater than 0.05 the hypothesis goodness-of-fit cannot be rejected.

Table 5. Copulas tested to model the dependence between severities and durations of the drought events for the Camanducaia River.

\begin{tabular}{cc}
\hline Copula & Copula's function and parameter ranger \\
\hline CLA & $C\left(u_{1}, u_{2}\right)=\left(u_{1}^{-\theta}+u_{2}^{-\theta}-1\right)^{-\frac{1}{\theta}}$ where $\theta \in(0, \infty)$ \\
FRA & $C\left(u_{1}, u_{2}\right)=-\frac{1}{\theta} \ln \left(1+\left(\frac{\left(e^{-\theta u_{1}}-1\right)\left(e^{-\theta u_{2}}-1\right)}{e^{-\theta}-1}\right)\right)$ where $\theta \in \bar{R} \backslash\{0\}$ \\
GUM & $C\left(u_{1}, u_{2}\right)=e^{-\left(\left(-\ln \left(u_{1}\right)\right)^{\theta}+\left(-\ln \left(u_{2}\right)\right)^{\theta}\right)^{\frac{1}{2}}}$ where $\theta \in[1, \infty)$ \\
JOE & $C\left(u_{1}, u_{2}\right)=\frac{u_{1} u_{2}}{1-\theta\left(1-u_{1}\right)\left(1-u_{2}\right)}$ where $\theta \in[1, \infty)$ \\
AMH & $C\left(u_{1}, u_{2}\right)=1-\left(\left(1-u_{1}\right)^{\theta}+\left(1-u_{2}\right)^{\theta}-\left(1-u_{1}\right)^{\theta}\left(1-u_{2}\right)^{\theta}\right)$ where $\theta \in(-1,1]$ \\
GAU & $C\left(u_{1}, u_{2}\right)=\int_{-\infty}^{\Phi^{-1}\left(u_{1}\right) \Phi^{-1}\left(u_{2}\right)} \frac{1}{2 \pi \sqrt{1-\theta^{2}}} e^{\left(\frac{-x^{2}-2 \theta x y+y^{2}}{2\left(1-\theta^{2}\right)}\right)_{d x d y} \text { where } \theta \in[-1,1]}$
\end{tabular}

Note: $\Phi^{-1}(\cdot)$ is the inverse of the univariate standard normal probability distribution. $\bar{R}=[-\infty,+\infty]$. 


\section{RESULTS AND DISCUSSION}

\section{Univariate analysis of the severities and durations}

Figures 6 and 7 compare the six theoretical cumulative distribution functions (CDF) with the empirical CDF calculated from the observed data of severities and durations of the drought events for the Camanducaia River from 1944 to 2016.

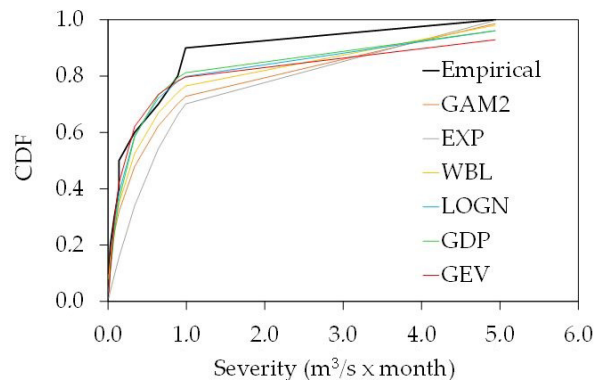

(a)

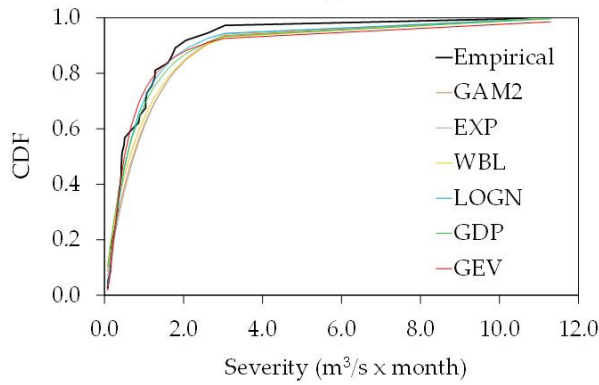

(c)
Tables 6 and 7 show the AIC values and the KS test's p-values for each probability distribution presented in Table 4 and tested to the severities and durations of the drought events. The p-values shown in Table 6 indicate that the hypothesis of goodness-of-fit of all probability distributions cannot be rejected for the severities considering all threshold levels under study.

Figure 6 corroborates with the p-values of Table 6 , showing that the theoretical CDFs are very close to the empirical CDFs. Thus,

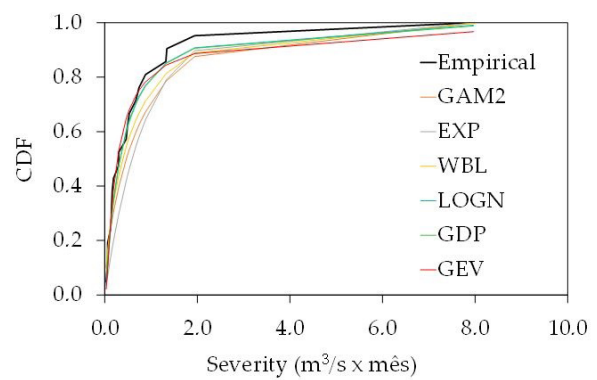

(b)

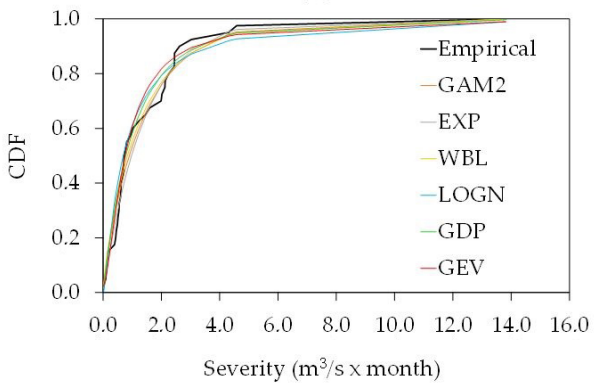

(d)

Figure 6. Severities' CDF of the drought events for the Camanducaia River from 1944 to 2016 considering the threshold levels: (a) P98, (b) P95, (c) P92 and (d) P90.

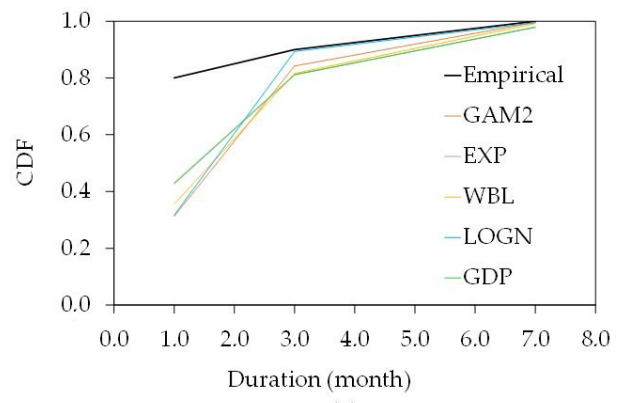

(a)

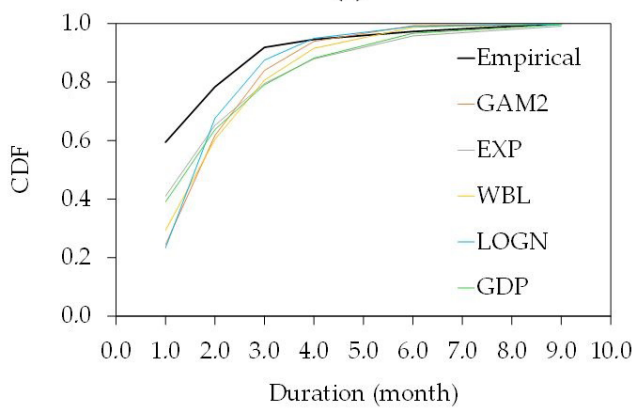

(c)

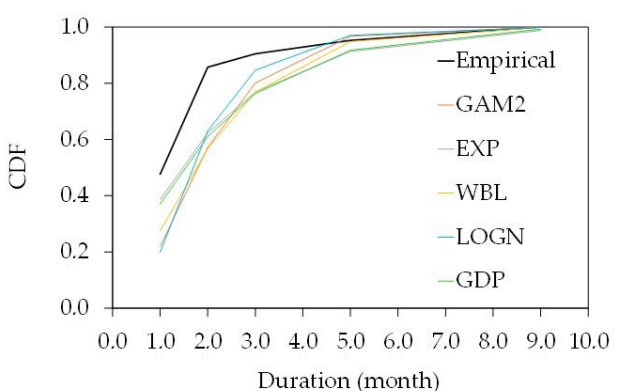

(b)

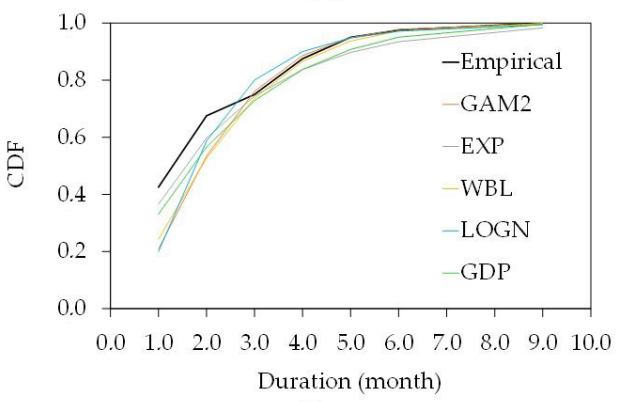

(d)

Figure 7. Durations' CDF of the drought events for the Camanducaia River from 1944 to 2016 considering the threshold levels: (a) P98, (b) P95, (c) P92 and (d) P90. 
Table 6. AIC values and KS test's p-values for each probability distribution tested to the drought events severities for the Camanducaia River from 1944 to 2016.

\begin{tabular}{|c|c|c|c|c|c|c|c|c|}
\hline \multirow{4}{*}{$\begin{array}{l}\text { Probability } \\
\text { distribution }\end{array}$} & \multicolumn{8}{|c|}{ Threshold levels } \\
\hline & \multicolumn{2}{|c|}{ P98 } & \multicolumn{2}{|c|}{ P95 } & \multicolumn{2}{|c|}{ P92 } & \multicolumn{2}{|c|}{$\mathbf{P 9 0}$} \\
\hline & \multirow{2}{*}{ AIC } & KS & \multirow{2}{*}{ AIC } & KS & \multirow{2}{*}{ AIC } & KS & \multirow{2}{*}{ AIC } & KS \\
\hline & & p-value & & p-value & & p-value & & p-value \\
\hline GAM2 & 15.77 & 0.84 & 38.50 & 0.78 & 83.05 & 0.20 & 110.33 & 0.52 \\
\hline EXP & 18.03 & 0.16 & 37.29 & 0.19 & 81.27 & 0.13 & 109.25 & 0.25 \\
\hline WBL & 14.90 & 0.95 & 33.46 & 0.98 & 81.50 & 0.48 & 109.21 & 0.76 \\
\hline LOGN & 14.17 & 1.00 & 28.79 & 1.00 & 71.00 & 0.75 & 109.13 & 0.89 \\
\hline GP & 14.65 & 0.84 & 30.13 & 0.97 & 76.58 & 0.74 & 106.75 & 0.84 \\
\hline GEV & 17.37 & 0.95 & 31.32 & 0.89 & 72.67 & 0.95 & 111.28 & 0.82 \\
\hline
\end{tabular}

Note: The bold values correspond to probability distribution selected.

Table 7. AIC values and KS test's p-values for each probability distribution tested to the drought events durations for the Camanducaia River from 1944 to 2016.

\begin{tabular}{|c|c|c|c|c|c|c|c|c|}
\hline \multirow{4}{*}{$\begin{array}{l}\text { Probability } \\
\text { distribution }\end{array}$} & \multicolumn{8}{|c|}{ Threshold levels } \\
\hline & \multicolumn{2}{|c|}{ P98 } & \multicolumn{2}{|c|}{ P95 } & \multicolumn{2}{|c|}{ P92 } & \multicolumn{2}{|c|}{ P90 } \\
\hline & \multirow{2}{*}{ AIC } & KS & \multirow{2}{*}{ AIC } & KS & \multirow{2}{*}{ AIC } & KS & \multirow{2}{*}{ AIC } & KS \\
\hline & & p-value & & p-value & & p-value & & $\mathrm{p}$-value \\
\hline GAM2 & 33.69 & 0.01 & 68.64 & 0.05 & 111.34 & 0.00 & 134.95 & 0.00 \\
\hline EXP & 33.76 & 0.08 & 74.10 & 0.18 & 123.18 & 0.14 & 145.08 & 0.25 \\
\hline WBL & 34.95 & 0.03 & 72.20 & 0.05 & 117.47 & 0.00 & 139.07 & 0.00 \\
\hline GP & 35.75 & 0.06 & 75.92 & 0,09 & 124.63 & 0.06 & 145.49 & 0.07 \\
\hline GEV & ()$^{*}$ & $(*)$ & $(*)$ & $(*)$ & $(*)$ & $(*)$ & $(*)$ & $(*)$ \\
\hline
\end{tabular}

Note: The bold values correspond to probability distribution selected.*Evaluation was not possible.

Table 8. Probability distributions of the severities and durations for the Camanducaia River drought events.

\begin{tabular}{|c|c|c|}
\hline \multirow{2}{*}{ Threshold level } & \multicolumn{2}{|c|}{ Probability distribution and estimated parameters } \\
\hline & Severity & Duration \\
\hline \multirow[t]{2}{*}{ P98 } & LOGN & EXP \\
\hline & $\hat{\mu}-1.462 \hat{\sigma} 1.737$ & $\hat{\lambda} 0.556$ \\
\hline \multirow[t]{2}{*}{ P95 } & LOGN & LOGN \\
\hline & $\hat{\mu}-1.127 \hat{\sigma} 1.347$ & $\hat{\mu} 0.498 \hat{\sigma} 0.588$ \\
\hline \multirow[t]{2}{*}{ P92 } & LOGN & EXP \\
\hline & $\hat{\mu}-0.569 \hat{\sigma} 1.057$ & $\hat{\lambda} 0.529$ \\
\hline \multirow[t]{2}{*}{ P90 } & GP & EXP \\
\hline & $\hat{\mu} 0.000 \hat{\xi} 0.262 \hat{\sigma} 1.023$ & $\hat{\lambda} 0.455$ \\
\hline
\end{tabular}

GAM2, EXP, WBL, LOGN, GP and GEV probability distributions represent well the severities of the drought events. According to the AIC values in Table 6 , the probability distributions with better fit to the severities of the drought events for the Camanducaia River are LOGN for the P98, P95 and P92 threshold levels and GP for the P90 threshold level.

Due to the discrete nature of the durations, not all probability distributions represent well its probabilistic behavior (Figure 7). For the durations, it was not possible to obtain a suitable fit for the GEV probability distribution for all threshold levels under study. Excluding GEV, Table 7 shows that the hypothesis of goodness-of-fit of all the probability distributions cannot be rejected for the P95 threshold level. For the P98, P92 and P90 threshold levels, the hypothesis of goodness-of-fit cannot be rejected only for the EXP and GP probability distributions. According to the AIC values, the probability distributions with a better fit to the durations of the drought events for the Camanducaia River are EXP for the P98, P92 and P90 threshold levels and LOGN for the P95 threshold level.

Table 8 shows, for each threshold level, the probability distributions selected and their estimated parameters to represent the probabilistic behavior of the severities and durations of the drought events for the Camanducaia River.

Thus, for the threshold levels under study (P98, P95, P92 and P90), the LOGN and EXP probability distributions are the most adequate to represent the probabilistic behavior of the severities and durations of the drought events for the Camanducaia River, with the exception of the P90 threshold level where the GP probability distribution was more adequate to the severities. 
Table 9. AIC values and GOF test's p-values for each copulas tested to represent jointly the severities and durations for the Camanducaia River drought events.

\begin{tabular}{|c|c|c|c|c|c|c|c|c|}
\hline \multirow{4}{*}{ Copula } & \multicolumn{8}{|c|}{ Threshold level } \\
\hline & \multicolumn{2}{|c|}{ P98 } & \multicolumn{2}{|c|}{ P95 } & \multicolumn{2}{|c|}{ P92 } & \multicolumn{2}{|c|}{ P90 } \\
\hline & \multirow{2}{*}{ AIC } & GOF & \multirow{2}{*}{ AIC } & GOF & \multirow{2}{*}{ AIC } & GOF & \multirow{2}{*}{ AIC } & GOF \\
\hline & & p-value & & p-value & & p-value & & p-value \\
\hline CLA & -1.02 & $*$ & -11.04 & 0.10 & -9.04 & 0.00 & -12.16 & 0.00 \\
\hline FRA & -4.52 & 0.28 & -12.96 & 0.34 & -24.82 & 0.47 & -37.62 & 0.10 \\
\hline GUM & -7.04 & 0.79 & -14.96 & 0.88 & -29.33 & 0.35 & -41.14 & 0.36 \\
\hline $\mathrm{JOE}$ & -8.14 & 0.90 & -12.74 & 0.45 & -29.85 & 0.17 & -43.20 & 0.28 \\
\hline AMH & -1.65 & 0.10 & -9.80 & 0.03 & -9.32 & 0.00 & -12.31 & 0.00 \\
\hline GAU & -5.16 & 0.36 & -15.89 & 0.56 & -25.79 & 0.31 & -33.44 & 0.17 \\
\hline
\end{tabular}

Note: The bold values correspond to the copula selected. *Evaluation was not possible.

\section{Bivariate analysis of the severities and durations}

Table 2 shows the main characteristics of the severities and durations of the drought events for the Camanducaia River. Kendall's $\tau$ and Spearman's $\rho$ indicate a significant dependence between the severities and durations, suggesting the joint modeling of these variables. Based on the univariate probability distributions in Table 8 , the copulas presented in Table 5 were tested to represent jointly the severities and durations of the drought events for the Camanducaia River.

Table 9 shows the AIC values and the GOF test's p-values for each copula tested. According to the AIC, the copulas with better fit are JOE for the P98, P92 and P90 threshold levels and GAU for the P95 threshold level.

According to the GOF test's p-values (Table 9), the hypothesis of the severities and durations being represented jointly by FRA, GUM, JOE and GAU copulas cannot be rejected for all threshold levels under study. The hypothesis of severities and durations being represented jointly by a CLA copula cannot be rejected for the P90 threshold level and by an AMH copula for the P95 threshold level. The results show that asymmetric copulas with upper tail dependency and symmetric copulas without tail dependency can represent suitably the joint behavior of the severities and durations of the drought events for the Camanducaia River.

Table 10 shows, for each threshold level, the estimated copulas' parameters selected (with better fit) to represent jointly the severities and durations of the drought events for the Camanducaia River.

Figure 8 shows the severities and durations observed during the drought events for the Camanducaia River, their joint probabilities (isolines) and the 2000 events simulated (pseudo-observations) based on the copulas in Table 10 .

Table 11 shows the $95 \%$ confidence intervals for the severities and average durations, and for the concordance measures between the severities and durations (Kendall's $\tau$ and Spearman's $\rho$ ). The confidence intervals were calculated from Monte Carlo simulations, where 100 samples, each with 2000 drought events, were generated from the Table 10 copulas. For the confidence intervals, the Shapiro-Wilk test was used to verify the normality hypothesis of the data of severity and average duration, Kendall's $\tau$ and Spearman's $\rho$, obtained from Monte Carlo simulations. The normality hypothesis cannot be rejected, because all p-values were greater than 0.05 .
Table 10. Copulas' parameters selected to represent jointly the severities and durations for the Camanducaia River drought events.

\begin{tabular}{ccc}
\hline Threshold level & Copula selected & $\begin{array}{c}\text { Estimates } \\
\text { parameter }(\hat{\boldsymbol{\theta}})\end{array}$ \\
\hline P98 & JOE & 2.772 \\
P95 & GAU & 0.729 \\
P92 & JOE & 2.895 \\
P90 & JOE & 3.735 \\
\hline
\end{tabular}

Table 11. 95\% confidence intervals for the severity and average duration and Kendall's $\tau$ and Spearman's $\rho$ of the drought events of the Camanducaia River based on the Table 10 copulas.

\begin{tabular}{ccccc}
\hline \multirow{2}{*}{ Statistics } & \multicolumn{4}{c}{ Threshold level } \\
\cline { 2 - 5 } & P98 & P95 & P92 & P90 \\
\hline Average severity & $0.88-1.28$ & $0.73-0.88$ & $0.94-1.04$ & $1.31-1.45$ \\
Average duration & $1.77-1.87$ & $1.90-2.00$ & $1.81-1.96$ & $2.12-2.28$ \\
Kendall's $\tau$ & $0.46-0.51$ & $0.50-0.54$ & $0.48-0.53$ & $0.57-0.61$ \\
Spearman's $\rho$ & $0.63-0.70$ & $0.69-0.74$ & $0.66-0.71$ & $0.76-0.80$ \\
\hline Note: Severity in $\left(\mathrm{m}^{3} / \mathrm{s} \times\right.$ month) and duration in (month).
\end{tabular}

Table 12. Ave, Max and Min values of the severities and durations and Kendall's $\tau$ and Spearman's $\rho$ values between the severities and durations of the simulated drought events for the Camanducaia River (pseudo-observations) from the Table 10 copulas.

\begin{tabular}{|c|c|c|c|c|c|}
\hline \multirow{2}{*}{\multicolumn{2}{|c|}{ Statistics }} & \multicolumn{4}{|c|}{ Threshold level } \\
\hline & & \multirow{2}{*}{$\begin{array}{c}\text { P98 } \\
0.97\end{array}$} & \multirow{2}{*}{$\begin{array}{r}\text { P95 } \\
0.85\end{array}$} & \multirow{2}{*}{$\begin{array}{l}\text { P92 } \\
0.99\end{array}$} & \multirow{2}{*}{$\begin{array}{c}\text { P90 } \\
1.43\end{array}$} \\
\hline Severity & Ave & & & & \\
\hline & Max & 52.49 & 40.01 & 32.87 & 73.08 \\
\hline & Min & 0.0008 & 0.01 & 0.02 & 0.001 \\
\hline \multirow[t]{3}{*}{ Duration } & Ave & 1.77 & 1.94 & 1.90 & 2.25 \\
\hline & Max & 12.61 & 18.62 & 17.98 & 16.77 \\
\hline & Min & 0.0008 & 0.26 & 0.0001 & 0.003 \\
\hline \multicolumn{2}{|c|}{ Kendall's $\tau$} & 0.46 & 0.52 & 0.49 & 0.59 \\
\hline \multicolumn{2}{|c|}{ Spearman's $\rho$} & 0.64 & 0.70 & 0.67 & 0.78 \\
\hline
\end{tabular}

Note: Severity in $\left(\mathrm{m}^{3} / \mathrm{s} \times\right.$ month) and duration in (month).

Table 12 shows the average (Ave), maximum (Max) and minimum (Min) values of the severities and durations for the 2000 simulated drought events for the Camanducaia River (pseudo-observations) and their respective Kendall's $\tau$ and Spearman's $\rho$. 


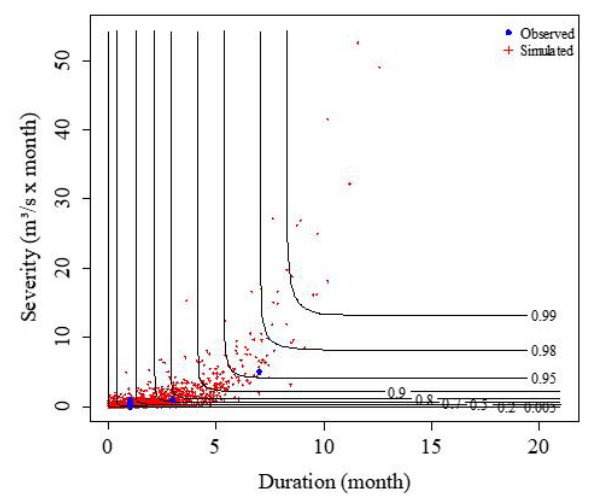

(a)

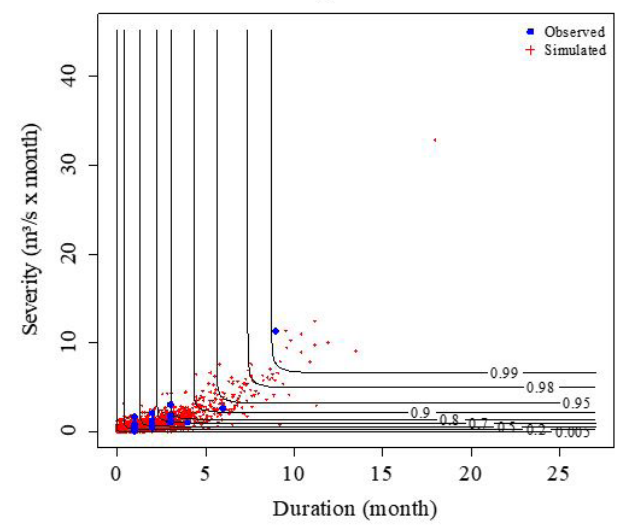

(c)

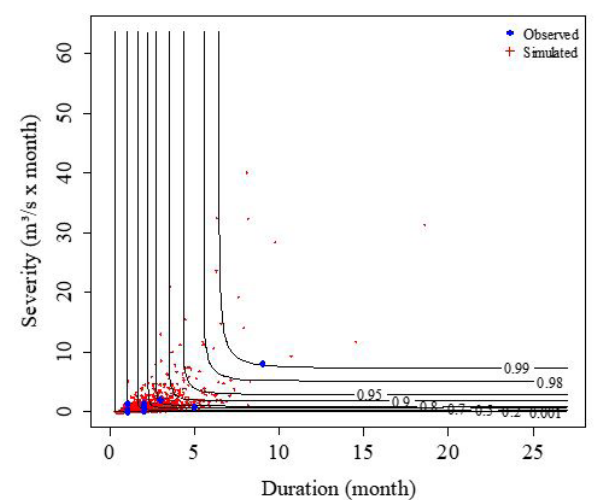

(b)

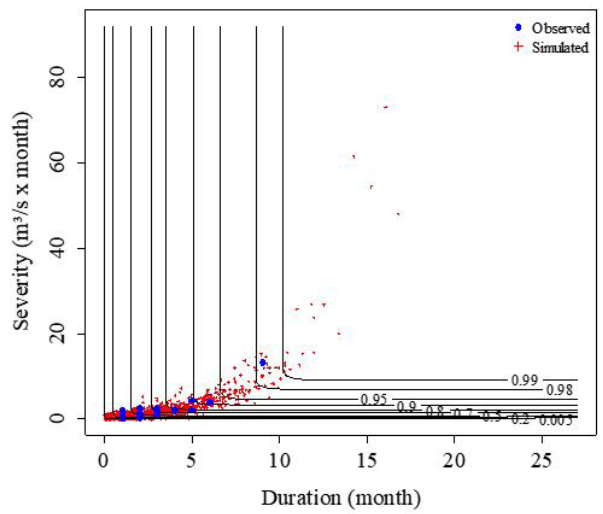

(d)

Figure 8. Observed and simulated drought events for the Camanducaia River and joint probabilities (isolines) considering the threshold levels: (a) P98, (b) P95, (c) P92 and (d) P90.

Box-Pierce and Ljung tests were used verified the hypothesis of independence of the data in series for the simulated severities and durations. According to the $\mathrm{p}$-values of the tests, all greater than 0.05 , the hypothesis of independence of the simulated data in the series cannot be rejected.

Comparing Tables 2, 11 and 12, in some cases, the expected values of severities and durations observed are not contained in confidence intervals calculated from the Table 10 copulas. It is occurs because the MLE used in this study to estimate of the probability distributions parameters, consists in maximizing the log-likelihood, unlike the Moment Matching Estimation (MME) method that consists in equalizing theoretical and empirical moments.

Thus, based on the values of the Tables 2, 11 and 12 the method presented in this study is able of simulating the occurrence of drought events for the Camanducaia River located in the southeast region of Brazil, preserving the laws of probability of the severities and durations and the dependency between both.

\section{DISCUSSION}

Considering the threshold levels under study, the results presented in the study show that the hypothesis of goodness-of-fit of the six probability distributions (GAM2, EXP, WLB, LOGN, GP and GEV), cannot be rejected to represent the behavior probabilistic of the severities for the Camanducaia River. For the durations, this fact occurs only for the EXP and GP.

With respect to the probability distributions with better fit to the historical data, we have for the severities the LOGN for P98, P95 and P92 threshold levels and GP for the P90 threshold level. For the durations, we have EXP for P98, P92 and P90 threshold levels and LOGN for the P95 threshold level.

It is important to note that due to the discrete nature of durations not all probability distributions tested in this study to represents suitably the probabilistic behavior of the variable. For the GEV probability distribution, it was not possible to obtain a suitable fit for all threshold levels under study. Researchers such as Michele et al. (2013) proposed a randomization technique to circumvent this problem, generating continuous samples of durations.

With regard to the joint representation of the probabilistic behavior of severities and durations of the drought events for the Camanducaia River, the use of the copulas JOE and GUM, asymmetric copulas with upper tail dependency, FRA and GAU copulas, symmetrical copulas without tail dependency, cannot be rejected for the all threshold levels under study. The CLA and AMH copulas can represent jointly the severities and durations only for the P95 and P98 threshold levels, respectively.

The results of the bivariate analysis show that, for the P98, P92 and P90 threshold levels, the joint representation hypothesis of the severities and durations cannot be rejected for JOE copula. 
For these same threshold levels, the second copula with the better fit is a GUM, followed by GAU and FRA copulas, respectively. For P95 threshold level, the GAU copula is the one with better fit, followed by GUM, FRA and JOE copulas, respectively.

Thus, it is important to emphasize that if the interest is in the extreme events, the asymmetric copulas with upper tail dependency are more suitable. If the extreme events are not relevant, the symmetric copulas without tail dependency can be used.

The limited number of historical observations of drought events can indicate a false perception of water safety, not indicating the possible risks of supply failure for human or other uses. The method presented in this study showed a strong potential to subsidize the risk analysis and, consequently, to assist in the planning and management of droughts in a river basin located in the southeast region of Brazil.

The results this study show that the coupling of the univariate probability distributions allowed the generation of a large number of drought events, with several combinations of severities and durations in comparison to the events observed from the historical data.

For the threshold levels under study, most observed drought events have durations of 1 to 2 months (from $70 \%$ to $86 \%$ ). This fact may lead decision-makers to a false perception of water safety. For example, for the P98 threshold level, considering the monthly streamflow data from 1944 to 2016, 80\% of the drought events have a duration of 1 and 2 months, with only two events with durations of 3 and 7 months and severities of 0.89 and $4.94 \mathrm{~m}^{3} / \mathrm{s} x$ month, respectively. However, when considering the sample of events generated by copula (in this case a Joe copula), a number of 348 events can occur to this durations with severities ranging from 0.004 to $14.49 \mathrm{~m}^{3} / \mathrm{s}$ x month. For the P95 threshold level, the observed data present only 3 drought events with durations of 3 to 9 months and severity ranging from 0.74 to $7.97 \mathrm{~m}^{3} / \mathrm{s} x$ month. Considering the events generated, 318 events may occur with durations of 3 to 9 months and with severity ranging from 0.09 to $32.99 \mathrm{~m}^{3} / \mathrm{s} x$ month. For the threshold level P95, the copula with better fit was to Gaussian.

In summary, the method presented in this study successfully reaches its goal, presenting itself as a useful tool for simulated the occurrence of drought events for the Camanducaia River located in the southeast region of Brazil.

\section{CONCLUSIONS}

This study investigated the univariate and bivariate probabilistic behavior of the hydrological drought events and presented a method for simulating this using Archimedeans and Gaussian copulas. More broadly, the results allow us to conclude that:

1. It is not possible to establish a single univariate and bivariate model to represent the behavior of the durations and severities of the drought events. Conditions such as, the size of the data sample observed and the threshold level directly influence the result of the analyzes;

2. The copulas can be easily used to represent the joint probabilistic behavior of the severities and durations of the drought events of a river and to simulate the occurrence of these events;

3. The simulation allowed us the generation of a large number of drought events, with several combinations of severities and durations in comparison to the events observed from the historical data of monthly average streamflow;

4. The dependence structure of the copulas influences the results of the simulations of the events. The asymmetric copulas with upper tail dependency are more suitable for the study of extremes events unlike symmetric copulas without tail dependency; and

5. This method can be easily applied in planning studies as a tool to generate scenarios for the analysis of risks of water resources systems.

\section{ACKNOWLEDGEMENTS}

This study had the financial support of the Sao Paulo Research - FAPESP in the form of a doctorate scholarship to the researcher Rogério de Almeida (Grant Number 02/02365-1).

\section{REFERENCES}

Akyuz, D. E., Bayazit, M., \& Onoz, B. (2012). Markov chain models for hydrological drought characteristics. Journal of Hydrometeorology, 13(1), 298-309. http://dx.doi.org/10.1175/JHM-D-11-019.1.

Azam, M., Maeng, S. J., Kim, H. S., \& Murtazaev, A. (2018). Copula-based stochastic simulation for regional drought risk assessment in South Korea. Water (Basel), 10(4), 2-29. http:// dx.doi.org/10.3390/w10040359.

Beran, M. A., \& Rodier, J. A. (1985). Hydrological aspects of droughts: a contribution to the international bydrological programme (Studies and Reports in Hydrology). Paris: UNESCO-WMO.

Cancelliere, A., \& Salas, J. D. (2004). Drought length properties for periodic-stochastic hydrologic data. Water Resources Research, 40(2), 1-13. http://dx.doi.org/10.1029/2002WR001750.

Chang, T. J. (1990). Effects of drought on streamflow characteristic. Journal of Irrigation and Drainage Engineering, 116(3), 332-341. http:/ / dx.doi.org/10.1061/(ASCE)0733-9437(1990)116:3(332).

Cunha, L., Vlachos, E., \& Yevjevich, V. (1983). Drought, environment and society. In V. Yevjevich, L. Cunha \& E. Vlachos. Coping with droughts (pp. 3-11). Littleton: Water Resources Publications.

Dodangeh, E., Shahedi, K., Shiau, J. T., \& Mirakbari, M. (2017). Spatial hydrological drought characteristics in Karkheh River Basin, southwest iran using copulas. Journal of Earth System Science, 126(6), 1-20. http://dx.doi.org/10.1007/s12040-017-0863-6.

Dracup, J. A., Lee, K. S., \& Paulson Junior, E. G. (1980a). On the definition drought. Water Resources Research, 16(2), 297-302. http:/ / dx.doi.org/10.1029/WR016i002p00297. 
Dracup, J. A., Lee, K. S., \& Paulson Junior, E. G. (1980b). On the statistical characteristics of drought events. Water Resources Research, 16(2), 289-296. http://dx.doi.org/10.1029/WR016i002p00289.

Ekanayake, E. M. R. S. B., \& Perera, K. (2014). Analysis of drought severity and duration using copulas in Anuradhapura, Siri Lanka. British Journal of Environment \& Climate Change, 4(3), 312-327. http://dx.doi.org/10.9734/BJECC/2014/14482.

Fan, L., Wang, H., Wang, C., Lai, W., \& Zhao, Y. (2017). Exploration of use of copulas in analyzing the relationship between precipitation and meteorological drought in Beijing, China. Advances in Meteorology, 33(9), 1-11. http://dx.doi.org/10.31497/zrzyxb.20170882.

Ganguli, P., \& Reddy, M. J. (2012). Risk assessment of drought in gujarat using bivariate copulas. Water Resources Management, 26(11), 3301-3327. http://dx.doi.org/10.1007/s11269-012-0073-6.

Genest, C., \& Favre, A. C. (2007). Everything you always wanted to know about copula modeling but were afraid to ask. Journal of Hydrologic Engineering, 12(4), 347-368. http://dx.doi.org/10.1061/ (ASCE)1084-0699(2007)12:4(347).

Genest, C., \& Rémillard, B. (2008). Validity of the parametric bootstrap for goodness-of-fit testing in semiparametric models. Annales de l'Institut Henri Poincare: Probabilites et Statistiques, 44(6), 1069-1127. http://dx.doi.org/10.1214/07-AIHP148.

Hamdi, Y., Chebana, F., \& Ouarda, T. B. M. J. (2016). Bivariate drought frequency analysis in the Medjerda River Basin Tunisia. Journal of Civil \& Environmental Engineering, 6(3), 1-11. http:// dx.doi.org/10.4172/2165-784X.1000227.

Hudson Junior, H. E., \& Hazen, R. (1964). Droughts and low streamflow. In V. T. Chow. Handbook of applied hydrology (pp. 181-18-26). New York: McGraw-Hill Book Company.

Joe, H. (1997). Multivariate models and dependence concepts. London: Chapman \& Hall. http:/ /dx.doi.org/10.1201/b13150.

Kwak, J., Kim, S., Kim, D., \& Kim, H. (2016a). Hydrological drought analysis based on copula theory. River Basin Management, 2016, 83-95. http://dx.doi.org/10.5772/64244.

Kwak, J., Kim, S., Kim, G., Singh, V. P., Park, J., \& Kim, H. S. (2016b). Bivariate drought analysis using streamflow reconstruction with tree ring indices in the Sacramento Basin, California, USA. Water (Basel), 8(4), 1-16. http://dx.doi.org/10.3390/w8040122.

Kwak, J., Kim, Y. S., Lee, J. S., \& Kim, H. S. (2012). Drought severity-duration-frequency analysis of hydrological drought based on copula theory. Hydrology Days, 2012, 81-89.

Mathier, L., Perreault, L., Bobée, B., \& Ashkar, F. (1992). The use of geometric and gamma-related distributions for frequency analysis of water deficit. Stochastic Hydrology and Hydraulics, 6(4), 239-254. http://dx.doi.org/10.1007/BF01581619.
Michele, C., \& Salvadori, G. (2003). A generalized pareto intensity-duration model of storm rainfall exploiting 2-copulas. Journal of Geophysical Research, 108(1), 1-11. http://dx.doi. org/10.1029/2002JD002534.

Michele, C., Salvadori, G., Vezzoli, R., \& Pecora, S. (2013). Multivariate assessment for droughts: frequency analysis and dynamic return period. Water Resources Research, 40(10), 6985-6994. http:/ / dx.doi. org/10.1002/wrcr.20551.

Millian, J., \& Yevjevich, V. (1971). Probabilities of observed droughts (Hydrology Paper, 50). Fort Collins: Colorado State University.

Mirabbasi, R., Fakheri-Fard, A., \& Dinpashoh, Y. (2011). Bivariate drought frequency analysis using the copula method. Theoretical and Applied Climatology, 108(1-2), 191-206. http://dx.doi.org/10.1007/ s00704-011-0524-7.

Mishra, A. K., \& Singh, V. P. (2010). A review of drought concepts. Journal of Hydrology (Amsterdam), 391(1-2), 202-216. http://dx.doi. org/10.1016/j.jhydrol.2010.07.012.

Nelsen, R. (2006). An introduction to copulas (2nd ed.). New York: Springer.

Panu, U. S., \& Sharma, T. C. (2009). Analysis of annual hydrological droughts: the case of Northwest Ontario, Canada. Hydrological Sciences Journal, 54(1), 29-42. http://dx.doi.org/10.1623/hysj.54.1.29.

Reddy, M. J., \& Ganguli, P. (2012). Application of copulas for derivation of drought severity-duration-frequency curves. Hydrological Processes, 26(11), 1672-1685. http://dx.doi.org/10.1002/hyp.8287.

Salas, J. D., Fu, C., Cancelliere, A., Dustin, D., Bode, D., Pineda, A., \& Vincent, E. (2005). Characterizing the severity and risk of drought in the Poudre River, Colorado. Journal of Water Resources Planning and Management, 131(5), 383-393. http://dx.doi.org/10.1061/ (ASCE)0733-9496(2005)131:5(383).

Salvadori, G., \& Michele, C. (2007). On the use of copulas in hydrology: theory and practice. Journal of Hydrologic Engineering, 12(4), 369-380. http:/ / dx.doi.org/10.1061/(ASCE)10840699(2007)12:4(369).

Salvadori, G., \& Michele, C. (2015). Multivariate real-time assessment of drought via copula-based multi-site hazard trajectories and fans. Journal of Hydrology (Amsterdam), 526, 101-115. http://dx.doi. org/10.1016/j.jhydrol.2014.11.056.

Salvadori, G., Michele, C. D., Kottegoda, N. T., \& Rosso, R. (2007). Extremes in nature. An approach using Copulas (Water Science and Technology Library Series; 56); Dordrecht: Springer. http:/ / dx.doi.org/10.1007/1-4020-4415-1.

Sen, Z. (1990). Critical drought analysis by second-order markov chain. Journal of Hydrology (Amsterdam), 120(1-4), 183-202. http:/ / dx.doi.org/10.1016/0022-1694(90)90149-R. 
Sharma, T. C. (1997). Estimation of drought severity on independent and dependent hydrologic series. Water Resources Management, 11(1), 35-49. http://dx.doi.org/10.1023/A:1007904718057.

Sharma, T. C., \& Panu, U. S. (2010). Analytical procedures for week hydrological droughts: a case of canadian rivers. Hydrological Sciences Journal, 55(1), 79-92. http://dx.doi.org/10.1080/02626660903526318.

Sharma, T. C., \& Panu, U. S. (2014). Modeling of hydrological drought durations and magnitudes: experiences on Canadian streamflows. Journal of Hydrology: Regional Studies, 1, 92-106.

She, D., \& Xia, J. (2018). Copulas-based drought characteristics analysis and risk assessment across the Loess Plateau of China. Water Resources Management, 32(2), 547-564. http://dx.doi.org/10.1007/ s11269-017-1826-z.

Shiau, J. T. (2006). Fitting drought duration and severity with twodimensional copulas. Water Resources Management, 20(5), 795-815. http://dx.doi.org/10.1007/s11269-005-9008-9.

Shiau, J. T., \& Modarres, R. (2009). Copula-based drought severityduration-frequency analysis in Iran. Meteorological Applications, 16(4), 481-489. http://dx.doi.org/10.1002/met.145.

Shiau, J. T., \& Shen, H. W. (2001). Recurrence analysis of hydrologic droughts of differing severity. Journal of Water Resources Planning and Management, 27(1), 30-40. http://dx.doi.org/10.1061/(ASCE)07339496(2001)127:1(30).

Shiau, J. T., Feng, S., \& Nadarajah, S. (2007). Assessment of hydrological droughts for the Yellow River, China, Using Copulas. Hydrological Processes, 21(16), 2157-2163. http://dx.doi.org/10.1002/ hyp.6400.

Sistema Integrado de Gerenciamento dos Recursos Hídricos SIGRH. (2017, February 6). São Paulo: SIGRH. Retrieved from http://www.sigrh.sp.gov.br

Sklar, M. (1959). Fonctions de répartition à n dimensions et leurs marges. Saint-Denis: Université Paris 8.

Tesfaye, Y. G. (2005). Seasonal time series models and their application to the modeling of river flows (Dissertation of master degree). Nevada: University of Nevada.
Tosunoglua, F., \& Onof, C. (2017). Joint modelling of drought characteristics derived from historical and synthetic rainfalls: Application of Generalized Linear Models and Copulas. Journal of Hydrology: Regional Studies, 14, 167-181.

Wang, Y., Li, C., Liu, J., Yu, F., Qiu, Q., Tian, J., \& Zhang, M. (2017). Multivariate analysis of joint probability of different rainfall frequencies based on copulas. Water (Basel), 9(3), 3-16. http://dx.doi.org/10.3390/w9030198.

Wijayaratne, L. H., \& Golub, E. (1991). Multiyear drought simulation. Water Resources Bulletin, 27(3), 387-395. http:/ /dx.doi. org/10.1111/j.1752-1688.1991.tb01438.x.

Wilhite, D. A., \& Glantz, M. H. (1985). Understanding the drought phenomenon: the role of definitions. Water International, 10(3), 111-120. http://dx.doi.org/10.1080/02508068508686328.

Yahiaoui, A., Touaibia, B., \& Bouvier, C. (2009). Frequency analysis of the hydrological drought regime: case of oued mina catchment in Western of Algeria. Revue Nature et Technologie, (1), 3-15.

Yevjevich, V. (1967). An objective approach to definitions and investigations of continental hydrological droughts (Hydrologic Paper, 23) Fort Collins: Colorado State University.

Zelenhasic, E., \& Salvai, A. (1987). A method of streamflow drought analysis. Water Resources Research, 23(1), 156-168. http:// dx.doi.org/10.1029/WR023i001p00156.

Zhao, P., Lü, H., Fu, G., Zhu, Y., Su, J., \& Wang, J. (2017). Uncertainty of hydrological drought characteristics with copulas functions and probability distributions: a case study of Weihe River, China. Water (Basel), 9(5), 1-15. http://dx.doi.org/10.3390/w9050334.

\section{Authors contributions}

Rogério de Almeida: This study is part of the author's doctoral thesis.

Paulo Sérgio Franco Barbosa: Advisor professor of the doctoral thesis of student Rogério de Almeida. 